\title{
Genetic differentiation of octopuses from different habitats near the Korean Peninsula and eastern China based on analysis of the mDNA cytochrome $C$ oxidase 1 gene
}

\author{
J.-H. Kang' ${ }^{1}$ J.-Y. Park ${ }^{1}$ and T.-J. Choi ${ }^{2}$ \\ ${ }^{1}$ Biotechnology Research Division, \\ National Fisheries Research and Development Institute, Busan, \\ Republic of Korea \\ ${ }^{2}$ Department of Microbiology, Pukyong National University, Busan, \\ Republic of Korea \\ Corresponding author: T.-J. Choi \\ E-mail: choitj@pknu.ac.kr
}

Genet. Mol. Res. 11 (4): 3988-3997 (2012)

Received July 5, 2012

Accepted October 2, 2012

Published November 21, 2012

DOI http://dx.doi.org/10.4238/2012.November.21.2

\begin{abstract}
Distributed along the coastal waters of Korea and China, Octopus minor is found in various habitats, including the mud flats in the southern and western coasts of the Korean Peninsula and the rocky areas around Jeju Island; however, the genetic relationships among the different populations are unknown and have not been studied. We compared 630-nucleotide sequences of the $\mathrm{COI}$ gene from $O$. minor specimens collected from five regions around the Korean Peninsula and three regions from eastern China in order to determine population structure and genetic relationships. Based on the sequences at 12 polymorphic sites in this region, 11 haplotypes were identified from 85 specimens. Individuals from Jeju Island had unique haplotypes, including two haplotypes not found in the other populations. Nucleotide
\end{abstract}


and haplotype diversity for all populations ranged from 0.03-0.37 and $0.20-0.64$, respectively. Pairwise $F_{\mathrm{ST}}$ values indicated significant genetic differences in populations from Korea and China. An UPGMA dendrogram showed separation of the eight populations into three clusters; one included only the Jeju population, another included the rest of the Korean populations and some from Dalian, China; a third cluster consisted of two other populations from China. We conclude that there are discrete genetic differences in $O$. minor from the different habitats, suggesting that the populations should be considered as management units in the ongoing recovery program.

Key words: Octopus minor; CO1; Genetic differentiation; Habitats

\section{INTRODUCTION}

The octopus accounts for more than one-third of the total number of known cephalopod mollusks in the order Octopoda, and there are approximately 300 recognized octopus species distributed along the coastal waters of Korea, China, and Japan. Octopus minor is commercially important in Korea and China, as are $O$. vulgaris, O. ocellatus, and O. aegina (Roper et al., 1984; Norman and Sweeney, 1997).

After octopus production in Korea peaked at nearly 15,000 metric tons in 1993, it rapidly decreased due to environmental destruction and overfishing, and thus, a recovery plan for the octopus was established in 2006. Successful restoration of the economically precious species requires an understanding of its genetic background and diversity; however, information is limited regarding octopuses around the Korean Peninsula.

The octopus lives in diverse oceanic habitats, including coral reefs, pelagic waters, and the ocean floor. Although octopuses are commonly found around the Korean Peninsula, they are identified by different Korean names depending on their habitats and the area in which they are captured. The southern and western coasts of the Korean Peninsula have welldeveloped mud flats, and the thin-legged octopuses captured in this area are known in Korea as 'sebal nakji', meaning octopus with thin legs. In contrast, octopuses around Jeju Island inhabit the rocky areas and are known in Korea as 'dol nakji', meaning octopus living in rocky areas. Octopuses in the deeper southern and western sea are known in Korea as 'tongbal nakji' because they are captured by bladderwort shaped traps called 'tongbal'. However, there has been no attempt at molecular differentiation of octopuses occurring around the Korean Peninsula.

The eastern coast of China and the Korean Peninsula is connected by the Yellow Sea Warm Current, which travels counterclockwise to the western coast of the Korean Peninsula and to the entrance of the Gulf of Bohai. Therefore, genetic relationships between octopus populations inhabiting these two countries are expected. In addition, the recent increase in the importation of live octopus from China may affect the genetic structure of the octopus population around the Korean Peninsula in the future.

The cytochrome $\mathrm{C}$ oxidase 1 (COI) gene in mitochondrial DNA (mtDNA) has been widely used because of its unique characteristics. mtDNA shows a higher base-substitution mutation rate compared to that in nuclear DNA (nDNA) (Tang et al., 2006). There are multiple copies of mtDNA compared to nDNA, making it easier to amplify by polymerase chain 
reaction (PCR). The $\mathrm{CO}$ gene has been used as the main barcoding target gene for species identification of many organisms (Rock et al., 2008; Smith et al., 2008), but this gene is also useful in phylogeographic studies within a single species (DeBoer et al., 2008; Li et al., 2009).

While the size of the $C O 1$ gene is approximately $1500 \mathrm{bp}$, only an internal region of about 600 bp is commonly used because it is variable enough to differentiate species and short enough to be sequenced in one reaction (Hebert et al., 2004).

In the present study, we analyzed $630 \mathrm{bp}$ of amplified $\mathrm{CO}$ gene DNA fragments to determine genetic differentiation and genetic structures within and between octopus populations from different habitats around the Korean Peninsula and China.

\section{MATERIAL AND METHODS}

\section{Sampling and DNA extraction}

A total of 85 wild octopus samples were collected from five localities around the Korean Peninsula and three regions from the Yellow Sea coast of northern China (Figure 1). Tissues from the legs of 9-17 individuals were preserved in 100\% ethanol at the sampling site, and then transported to the laboratory for DNA extraction. Tissue $(20 \mathrm{mg})$ was homogenized in lysis buffer (MFX-2000, Toyobo, Osaka, Japan) containing $20 \mathrm{mg} / \mathrm{mL}$ proteinase $\mathrm{K}$, and total DNA was then isolated using a Mag Extractor MFX-6100 automated DNA extraction system (Toyobo). The extracted genomic DNA was quantified using a Nanodrop ND-1000 spectrophotometer (Thermo Fisher Scientific, Barrington, IL, USA) and stored at $-20^{\circ} \mathrm{C}$.

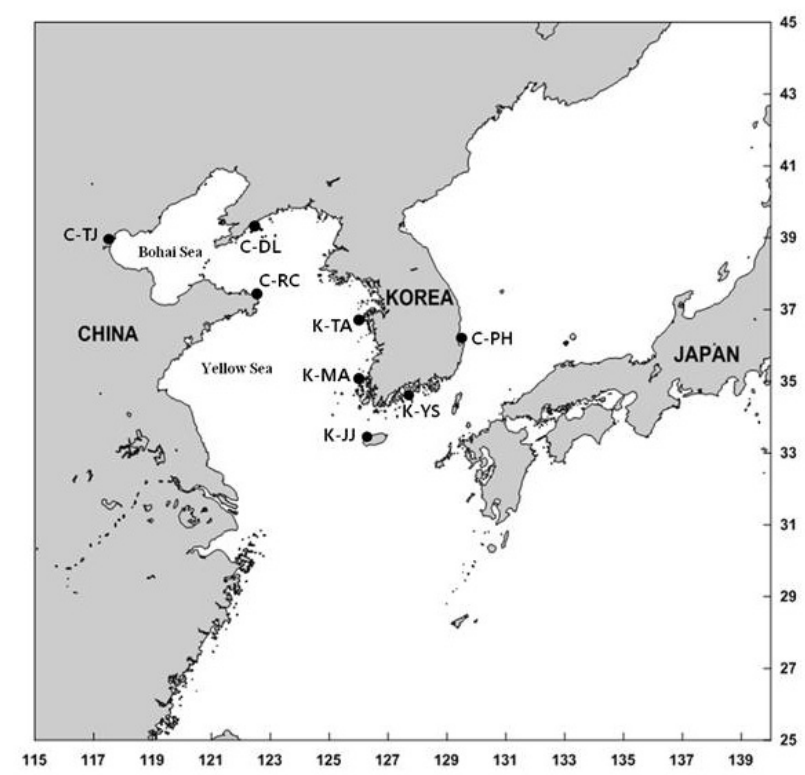

Figure 1. Geographical map showing locations and abbreviated names of Octopus minor samples from Korea and China. The prefixes $\mathrm{K}$ and $\mathrm{C}$ in the abbreviations indicate Korea and China, respectively. The abbreviations are as follow: K-TA (Taean), K-MA (Mooan), K-YS (Yeosu), K-JJ (Jeju), K-PH (Pohang), C-TJ (Tianjin), C-DL (Dalian), and C-RC (Rongcheng). 


\section{PCR and sequence analysis}

Primers HCO2198 and LCO1490, described by Folmer et al. (1994), were used for the amplification of the $C O 1$ gene. PCR amplification was performed in a $30-\mu \mathrm{L}$ reaction mixture containing $3 \mu \mathrm{L}$ template DNA, $1 \mu \mathrm{L} 10 \mathrm{pM} / \mu \mathrm{L}$ each of forward and reverse primer, $3 \mu \mathrm{L} 10 \mathrm{X}$ Taq PCR buffer, $2.4 \mu \mathrm{L} 2.5 \mathrm{mM}$ dNTP mixture, and $0.6 \mu \mathrm{L} 5 \mathrm{U} / \mu \mathrm{L}$ Taq DNA polymerase using a thermocycler (PTC-220, Bio-Rad, USA). PCR conditions were as follows: $10 \mathrm{~min}$ at $94^{\circ} \mathrm{C}$, followed by 35 cycles of $1 \mathrm{~min}$ at $94^{\circ} \mathrm{C}, 1 \mathrm{~min}$ at $51^{\circ} \mathrm{C}$, and $1 \mathrm{~min}$ at $72^{\circ} \mathrm{C}$, with a final extension of $5 \mathrm{~min}$ at $72^{\circ} \mathrm{C}$. After confirmation of the PCR product on an agarose gel, DNA fragments of about $630 \mathrm{bp}$ were isolated from the gel using the QIAquick PCR purification kit (Qiagen) and sequenced using the 3130XL Genetic Analyzer (Applied Biosystems, Foster City, CA, USA) with the Prism Big Dye Terminator Cycle Sequencing kit.

\section{Data analysis}

DNA sequences were analyzed by the DNA sequencing analysis software (Applied Biosystems) and assembled using the SeqMan software (DNASTAR Lasergene 8 package). The haplotype and genetic distance were determined by the MEGA 4 program (Tamura et al., 2007). Haplotype diversity and nucleotide diversity were calculated using DnaSP version 4.0 (Rozas, 2003). Population structure was investigated using analysis of molecular variance (AMOVA) and a possible geographical pattern in the distribution of genetic variability was analyzed using $F_{\mathrm{ST}}$ estimates (Weir and Cookerham, 1984). Median-joining network analyses were performed using the Network version 4.1 software package (Bandelt et al., 1999). The genetic distance matrices were used to construct an unweighted pair group method with arithmetic mean (UPGMA) dendrogram with the PHYLIP ver. 3.5 software package (Felsenstein, 1989).

\section{RESULTS}

\section{Sequence analysis}

PCR products of approximately $630 \mathrm{bp}$ were obtained by amplification with the HCO2198 and LCO1490 primers. Sequence analysis of PCR products showed over $99 \%$ sequence identity to the mtDNA COI gene of $O$. minor (GenBank accession No. AB430541). The most frequent sequence was named haplotype 1, as shown in Figure 2. This sequence showed $89.5 \%$ nucleotide similarity to the mtDNA CO1 gene of Callioctopus ornatus (AB430528) and $87.4 \%$ similarity to that of $C$. luteus (AB385874), belonging to the same genus.

Twelve variable sites were identified from 85 individuals, yielding 11 haplotypes (Table 1). The variable sites at 288 and 459 were transversions ( $\mathrm{A} \leftrightarrow \mathrm{T}, \mathrm{G} \leftrightarrow \mathrm{T})$, whereas the remaining variations were transitions $(A \leftrightarrow G, C \leftrightarrow T)$. No insertions or deletions were found. Variations at 247 and 322 occurred in the second position of the codons, and the remaining variations were in the third position. The $\mathrm{G} \rightarrow$ A change at 322 resulted in an amino acid change from alanine to threonine, whereas the remaining nucleotide changes did not cause amino acid substitutions. 


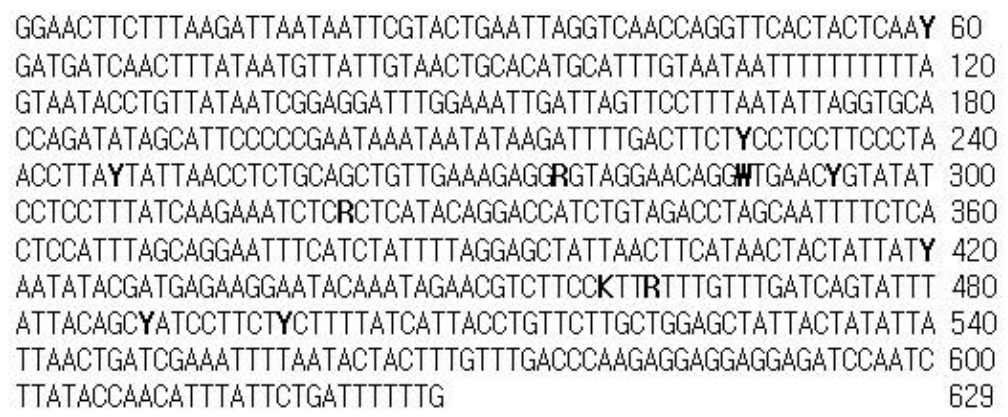

Figure 2. Nucleotide sequence of haplotype 1 from a fragment of the mitochondrial DNA cytochrome oxidase subunit 1 (CO1) gene of Octopus minor. The variable sites shown in Table 1 are depicted in bold mixed base code as follow; Y (C,T), R (A,G), W (A,T), K (G,T).

Table 1. Nucleotide polymorphisms observed in the $\mathrm{CO} 1$ gene and their frequencies.

\begin{tabular}{|c|c|c|c|c|c|c|c|c|c|c|c|c|c|}
\hline Variable site & 060 & 228 & 247 & 276 & 288 & 294 & 322 & 420 & 459 & 462 & 489 & 498 & $\mathrm{~N}$ \\
\hline Hap 01 & $\mathrm{~T}$ & $\mathrm{~T}$ & $\mathrm{C}$ & G & $\mathrm{A}$ & $\mathrm{T}$ & G & $\mathrm{C}$ & $\mathrm{T}$ & G & $\mathrm{T}$ & $\mathrm{C}$ & 43 \\
\hline Hap 02 & - & - & $\mathrm{T}$ & - & • & - & - & - & - & - & - & - & 7 \\
\hline Hap 03 & - & - & • & $\mathrm{A}$ & - & • & - & - & • & - & - & - & 2 \\
\hline Hap 04 & - & - & - & - & - & - & $\mathrm{A}$ & - & - & - & - & - & 1 \\
\hline Hap 05 & - & - & $\mathrm{T}$ & - & - & - & $\cdot$ & - & - & A & - & - & 1 \\
\hline Hap 06 & $\mathrm{C}$ & - & $\mathrm{T}$ & $\mathrm{A}$ & - & $\mathrm{C}$ & - & - & - & $\cdot$ & - & $\mathrm{T}$ & 18 \\
\hline Hap 07 & - & $\mathrm{C}$ & $\mathrm{T}$ & $\mathrm{A}$ & - & $\mathrm{C}$ & - & - & • & - & - & $\mathrm{T}$ & 7 \\
\hline Hap 08 & - & • & $\mathrm{T}$ & $\mathrm{A}$ & $\mathrm{T}$ & $\mathrm{C}$ & - & - & - & • & • & $\mathrm{T}$ & 1 \\
\hline Hap 09 & - & $\mathrm{C}$ & $\mathrm{T}$ & A & - & $\mathrm{C}$ & - & $\mathrm{T}$ & • & • & - & $\mathrm{T}$ & 3 \\
\hline Hap 10 & $\mathrm{C}$ & - & $\mathrm{T}$ & A & - & $\mathrm{C}$ & • & - & $\mathrm{G}$ & - & - & $\mathrm{T}$ & 1 \\
\hline Hap 11 & • & • & $\mathrm{T}$ & $\bullet$ & • & $\mathrm{C}$ & • & • & • & A & $\mathrm{C}$ & $\mathrm{T}$ & 1 \\
\hline Total & & & & & & & & & & & & & 85 \\
\hline
\end{tabular}

\section{Variation between haplotypes}

Haplotype frequencies of the COI fragment and their distribution among the eight populations are shown in Table 2. Haplotype 1 was the most common and was observed in six of the eight populations, with an overall proportion of $50.1 \%$ in the total samples. Haplotype 6 was observed with $21 \%$ frequency, whereas haplotypes $4,5,8,10$, and 11 were each found only once in all populations.

With the exception of haplotype 1, other haplotypes were found in populations that were either from Korea or China. All individuals in the K-PH population from Pohang exhibited only haplotype 1, in contrast to the K-JJ population from Jeju Island with haplotypes 7 and 9, which were not found in other populations. With the exception of the K-PH population, which had only haplotype 1 , the haplotype diversity ranged from 0.20 to 0.64 and the nucleotide diversity ranged from 0.03 to 0.37 . The populations from China showed higher values in haplotype and nucleotide diversity compared to the populations from Korea. Based on the nucleotide divergences identified in this study, a median network among the haplotypes indicated that the haplotypes were not closely related, except for haplotype 1, which was shared by populations from Korea and China (Figure 3). 
Table 2. Summary of the distribution of haplotypes, nucleotide diversity, and number of polymorphic sites among 8 populations of Octopus minor.

\begin{tabular}{|c|c|c|c|c|c|c|c|c|}
\hline & K-JJ & K-MA & K-TA & K-YS & K-PH & C-DL & C-RC & C-TJ \\
\hline Hap 01 & . & 0.89 & 0.9 & 0.7 & 1 & 0.6 & 0.12 & . \\
\hline Hap 02 &. &. & . & . & . & 0.1 & 0.25 & 0.25 \\
\hline Hap 03 & . & . & . & 0.2 & . & . & . & . \\
\hline Hap 04 & . & . & 0.1 & . & . & . & . & . \\
\hline Hap 05 & . & . & . & . & . & 0.1 & . & . \\
\hline Hap 06 & . & . & . & . & . & 0.2 & 0.59 & 0.75 \\
\hline Hap 07 & 0.7 & . & . & . & . &. & . & . \\
\hline Hap 08 & . & 0.11 & . & . & . & . & . & . \\
\hline Hap 09 & 0.3 & . &. & . & . & . & . & . \\
\hline Hap 10 & . & . & . & . & . & . & . & . \\
\hline Hap 11 & . & 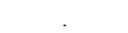 & 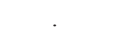 & 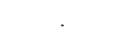 & 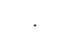 & . & 0.06 & . \\
\hline No. of sample & 10 & 9 & 10 & 10 & 11 & 10 & 17 & 8 \\
\hline No. of polymorphic site & 5 & 7 & 6 & 7 & 5 & 7 & 8 & 6 \\
\hline No. of haplotype & 2 & 2 & 2 & 3 & 1 & 4 & 4 & 2 \\
\hline Nucleotide diversity (\%) & $0.08 \pm 0.08$ & $0.18 \pm 0.15$ & $0.03 \pm 0.05$ & $0.25 \pm 0.19$ & 0 & $0.35 \pm 0.24$ & $0.37 \pm 0.24$ & $0.28 \pm 0.21$ \\
\hline Haplotype diversity & $0.47 \pm 0.13$ & $0.22 \pm 0.17$ & $0.20 \pm 0.15$ & $0.51 \pm 0.16$ & 0 & $0.64 \pm 0.15$ & $0.62 \pm 0.11$ & $0.43 \pm 0.17$ \\
\hline
\end{tabular}

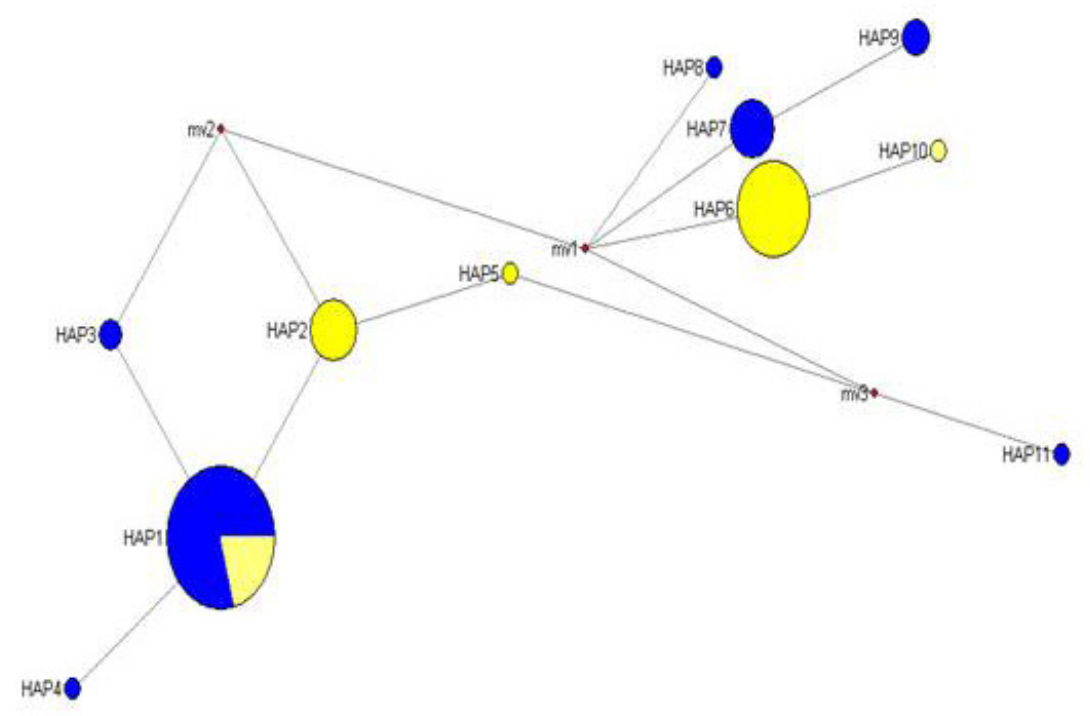

Figure 3. Median-network showing the phylogenetic relationships among the 11 haplotypes of the mtDNA COI gene. The size of each circle is an approximate indication of the haplotype frequency. The blue and yellow circles represent haplotypes found in populations from Korea and China, respectively.

\section{Population genetic structure and relationships}

AMOVA results showed partitioning of the populations with significant variance ( $\mathrm{P}$ $<0.001$ ). However, only $14.79 \%$ of variation was attributed to its distribution between the groups of Korea and China, in contrast to 45.30 and $39.91 \%$, which were attributed to distribution among populations within groups and within populations, respectively (Table 3). 
Table 3. Analysis of molecular variance for the $\mathrm{CO} 1$ gene between Korea and China groups of Octopus minor populations.

\begin{tabular}{lcccc}
\hline Source of variation & d.f. & Sum of squares & Variance components & $\%$ of variation \\
\hline Among groups & 1 & 18.246 & 0.22851 & 14.79 \\
Among populations within groups & 6 & 47.097 & 0.69977 & 45.30 \\
Within populations & 77 & 47.48 & 0.61662 & 39.91 \\
Total & 84 & 112.824 & 1.5449 & 100 \\
\hline
\end{tabular}

d.f. $=$ degrees of freedom.

Genetic differentiation between $O$. minor populations from Korea and China was assessed using $F_{\text {ST }}$ pairwise comparisons and genetic distance (Table 4). Except for the K-JJ, the populations from Korea showed high $F_{\mathrm{ST}}$ values ranging from 0.109 to 0.999 , indicating that variations within samples were smaller than variations between samples. Among the 15 pairwise comparisons between the Korean and Chinese populations, 13 pairs were significant, except for the K-YS and C-DL pairs and the K-MA and C-DL pairs. Among the three pairs from the Chinese populations, two were significant.

Table 4. Pairwise $F_{\mathrm{ST}}$ values (above diagonal) and genetic distance (below diagonal) between the eight populations of Octopus minor.

\begin{tabular}{llllccccc}
\hline Population & K-JJ & K-MA & K-TA & K-YS & K-PH & C-DL & C-RC & C-TJ \\
\hline K-JJ & & $0.845^{*}$ & $0.939^{*}$ & $0.803^{*}$ & $0.959^{*}$ & $0.716^{*}$ & $0.522^{*}$ & $0.631^{*}$ \\
K-MA & 0.021 & & 0.009 & -0.073 & 0.023 & -0.004 & $0.479^{*}$ & $0.636^{*}$ \\
K-TA & 0.025 & 0.000 & & 0.025 & 0.010 & $0.159^{*}$ & $0.606^{*}$ & $0.786^{*}$ \\
K-YS & 0.020 & 0.000 & 0.000 & & 0.038 & -0.009 & $0.458^{*}$ & $0.594^{*}$ \\
K-PH & 0.025 & 0.000 & 0.000 & 0.000 & & $0.186^{*}$ & $0.627^{*}$ & $0.819^{*}$ \\
C-DL & 0.017 & 0.001 & 0.002 & 0.001 & 0.002 & & $0.280^{*}$ & $0.410^{*}$ \\
C-RC & 0.009 & 0.009 & 0.012 & 0.009 & 0.012 & 0.005 & -0.068 \\
C-TJ & 0.009 & 0.013 & 0.016 & 0.013 & 0.016 & 0.008 & 0.000 & \\
\hline
\end{tabular}

*Significant $F_{\mathrm{ST}}$ value $(\mathrm{P}<0.05)$.

The phylogenetic tree showing the genetic relationship between the populations is shown in Figure 4. The eight populations were separated into three main clusters with one subcluster. The K-JJ population from Jeju Island formed a separate cluster. The remaining Korean populations formed another cluster with a subcluster including the C-DL population from China. The other two Chinese populations, C-RC and C-TJ, formed another cluster.

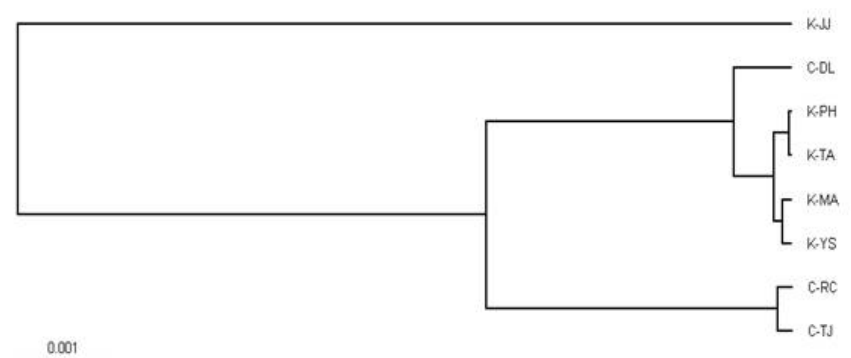

Figure 4. UPGMA tree of Octopus minor from five populations from Korea and three from China based on the mtDNA CO1 gene. 


\section{DISCUSSION}

The genetic structure and relationship of three octopus populations from China and five populations from Korea were analyzed using the partial sequence of the $\mathrm{CO} 1$ gene, which is essential for successful recovery and long-term conservation, especially because of their connection by ocean currents and the recent uncontrolled introduction of marine species from China to Korea.

Octopuses around the Korean Peninsula have different names depending on their habitats, so their taxonomy is confusing. The $\mathrm{CO} 1$ gene fragment obtained in this study showed $99 \%$ sequence identity to that of the $O$. minor sequence deposited in GenBank (AB430541). Also, it showed 89.5 and $87.4 \%$ nucleotide identity to C. ornatus and C. luteus, respectively, which are known to be the most closely related species according to a recent study based on the CO1 gene (Kaneko et al., 2011). These results indicate that the octopuses around Korean Peninsula belong to the same species despite their habitats and different Korean names.

Within the 630-bp fragment, 12 variable sites were recognized and 11 haplotypes were determined as shown in Table 1. In the haplotype analysis, the K-JJ population was unique in two features. First, haplotype 1, which was the most common and found in 6 populations, was not found in the K-JJ population. In addition, the K-JJ population had haplotypes 7 and 9 , which were not found in the other populations.

Except for the C-DL and C-RC populations, all populations studied showed low haplotype and nucleotide diversity (Table 2), and belonged to category 1, as defined by Grant and Bowen (1998). The C-DL and C-RC populations belonging to category 2 showed higher haplotype diversity $(0.64$ and 0.62 , respectively) and nucleotide diversity $(0.35$ and 0.37 , respectively), although nucleotide diversity remained low in the defined diversity range of $0-10 \%$ (Grant and Bowen, 1998). Categories 1 and 2 are common in fish, and the shallow divergence is due to population bottleneck and recent population growth.

Phylogenetic analysis showed clustering of the haplotypes into three clusters. Except for the population from Jeju Island, the Korean populations formed a cluster with the C-DL population from China. Two Chinese populations, C-TJ and C-RC, formed another cluster. The formation of three clusters may be explained by their natural habitat and the distance and ocean current between the Korean Peninsula and the east coast of China and the Gulf of Bohai. As described earlier, the octopus around Jeju Island inhabits rocky areas, in contrast to the populations from the south and west coast of the Korean peninsula, which inhabit muddy flats. After separation of the initial populations, octopuses in the different habitats evolved independently. This was further supported by the AMOVA results, which showed that the genetic variance was largely attributed to the differences between or within the populations rather than between groups of China or Korea.

The close relationship between the Korean and C-DL populations can be explained by the current in the Yellow Sea. On the western coast of the Korean Peninsula, the Yellow Sea Warm Current, a branch stream of the Tsushima Current, flows counterclockwise to the western coast of the Korean Peninsula and to the entrance of the Gulf of Bohai, the location of the C-DL sampling site (Pang et al., 1992). The strength of this current is relatively weak, as the current rarely reaches inside the Gulf of Bohai (Pang and Kim, 1998). The China coastline waters flowing southward can connect the C-TJ and C-RC populations. Therefore, it seems that the octopus populations around the Korean Peninsula and China have evolved separately with 
limited genetic exchange by ocean currents. This separation can be seen in the median network of Figure 3, which shows no clear connection of the haplotypes. Similar genetic separation has been observed in the analysis of the $16 \mathrm{~S}$ rRNA of octopus and microsatellite markers of sea cucumber from Korea and China (Kim et al., 2009; Kang et al., 2011).

In contrast to $O$. minor, phylogenetic analysis of Feneropenaeus chinensis in the same area showed a star-like median network, suggesting the existence of a recent population expansion from a common origin ( $\mathrm{Li}$ et al., 2009). In their recent analyses of population structure of F. chinensis in the Yellow Sea and the Gulf of Bohai using the CO1 gene, Li et al. (2009) found no significant differences for $F$. chinensis in this area. They also found that a specific haplotype was shared by all populations in this area. A possible reason for this observation was the high degree of larval dispersal and recent population expansion. Khamnamtong et al. (2009) reported significant genetic differentiation in 6 Penaeus modon populations in Thailand, which was significantly correlated with the geographic distances. In this case, larval dispersal was limited by the presence of physical barriers. These two observations coincide with our results, which indicate the presence of genetic differences between $O$. minor populations from China and Korea, with limited habitat and reproduction area and short time period of larval dispersion.

Although further analysis with more populations and samples is necessary, these results suggest that $O$. minor specimens living in different habitats in Korea and China need to be regarded as different 'management units' in future recovery plans.

\section{ACKNOWLEDGMENTS}

Research supported by the National Fisheries Research and Development Institute (NFRDI) in Korea (\#RP-2012-BT-007).

\section{REFERENCES}

Bandelt HJ, Forster P and Rohl A (1999). Median-joining networks for inferring intraspecific phylogenies. Mol. Biol. Evol. 16: 37-48.

DeBoer TS, Subia MD, Erdmann MV, Kovitvongsa K, et al. (2008). Phylogeography and limited genetic connectivity in the endangered boring giant clam across the Coral Triangle. Conserv. Biol. 22: 1255-1266.

Felsenstein J (1989). PHYLIP - phylogeny inference package (version 3.2). Cladistics 5: 164-166.

Folmer O, Black M, Hoeh W, Lutz R, et al. (1994). DNA primers for amplification of mitochondrial cytochrome c oxidase subunit I from diverse metazoan invertebrates. Mol. Mar. Biol. Biotechnol. 3: 294-299.

Grant WS and Bowen BW (1998). Shallow population histories in deep evolutionary lineages of marine fishes: insights from sardines and anchovies and lessons for conservation. J. Heredity 89: 415-426.

Hebert PD, Penton EH, Burns JM, Janzen DH, et al. (2004). Ten species in one: DNA barcoding reveals cryptic species in the Neotropical skipper butterfly Astraptes fulgerator. Proc. Natl. Acad. Sci. U. S. A. 101: 14812-14817.

Kaneko N, Kubodera T and Iguchi A (2011). Taxonomic study of shallow-water octopus (Cephalopoda: Octopodidae) in Japan and adjacent waters using mitochondrial genes with perspectives on octopus DNA barcoding. Malacologia 54: $97-108$.

Kang JH, Kim YK, Kim MJ, Park JY, et al. (2011). Genetic differentiation among populations and color variants of sea cucumbers (Stichopus japonicus) from Korea and China. Int. J. Biol. Sci. 7: 323-332.

Khamnamtong B, Klinbunga S and Menasveta P (2009). Genetic diversity and geographic differentiation of the giant tiger shrimp (Penaeus monodon) in Thailand analyzed by mitochondrial COI sequences. Biochem. Genet. 47: 42-55.

Kim JI, Oh TY, Seo YI and Cho ES (2009). Population genetic structure of Octopus minor Sasaki from Korea and China based on a partial sequencing of mitochondrial 16S rRNA. Korean J. Life Sci. 19: 711-719.

Li YL, Kong XY, Yu ZN, Kong J, et al. (2009). Genetic diversity and historical demography of Chinese shrimp 
Feneropenaeus chinensis in Yellow Sea and Bohai Sea based on mitochondrial DNA analysis. Afr. J. Biotechnol. 8: 1193-1202.

Norman MD and Sweeney MJ (1997). The shallow-water octopuses (Cephalopoda: Octopodidae) of the Philippines. Invertebr. Taxon. 11: 89-140.

Pang IC and Kim KH (1998). Seasonal variation of water mass distributions in the eastern Yellow Sea and the Yellow Sea warm current. J. Korean Soc. Oceanogr. 33: 41-52.

Pang IC, Rho HK and Kim TH (1992). Seasonal variation of water mass distributions and their causes in the Yellow Sea, the East China Sea and the adjacent seas of Cheju Island. Bull. Korean Fish. Soc. 25: 151-163.

Rock J, Costa FO, Walker DI, North AW, et al. (2008). DNA barcodes of fish of the Scotia Sea, Antarctica, indicate priority groups for taxonomic and systematics. Antarct. Sci. 20: 253-262.

Roper CFE, Sweeney MJ and Nauen CE (1984). Cephalopods of the World. Food and Agriculture Organization. Rome, 3: 277 .

Rozas J (2003). DnaSP: DNA polymorphism analyses by the coalescent and other methods. Bioinformatics 19: 2496-2497.

Smith MA, Poyarkov NA Jr and Hebert PD (2008). DNA barcoding: CO1 DNA barcoding amphibians: take the chance, meet the challenge. Mol. Ecol. Resour. 8: 235-246.

Tamura K, Dudley J, Nei M and Kumar S (2007). MEGA4: Molecular Evolutionary Genetics Analysis (MEGA) software version 4.0. Mol. Biol. Evol. 24: 1596-1599.

Tang Q, Liu H, Mayden R and Xiong B (2006). Comparison of evolutionary rates in the mitochondrial DNA cytochrome $\mathrm{b}$ gene and control region and their implications for phylogeny of the Cobitoidea (Teleostei: Cypriniformes). Mol. Phylogenet. Evol. 39: 347-357.

Weir BD and Cockerham CC (1984). Estimating F-statistics for the analysis of population structure. Evolution 38: 13581370. 